\title{
Mortality of patients infected with HIV in the intensive care unit (2005 through 2010): significant role of chronic hepatitis $C$ and severe sepsis
}

\author{
José Medrano ${ }^{1,2+}$, Alejando Álvaro-Meca ${ }^{3 \dagger}$, Alexandre Boyer ${ }^{4}$, María A Jiménez-Sousa ${ }^{5}$ and Salvador Resino ${ }^{5 *}$
}

\begin{abstract}
Introduction: The combination antiretroviral therapy (CART) has led to decreased opportunistic infections and hospital admissions in human immunodeficiency virus (HIV)-infected patients, but the intensive care unit (ICU) admission rate remains constant (or even increased in some instances) during the cART era. Hepatitis C virus (HCV) infection is associated with an increased risk for hospital admission and/or mortality (particularly those related to severe liver disease) compared with the general population. The aim of this study was to assess the mortality among HIV-infected patients in ICU, and to evaluate the impact of HIV/HCV coinfection and severe sepsis on ICU mortality.

Methods: We carried out a retrospective study based on patients admitted to ICU who were recorded in the Minimum Basic Data Set (2005 through 2010) in Spain. HIV-infected patients (All-HIV-group $(n=1,891)$ ) were divided into two groups: HIV-monoinfected patients (HIV group $(n=1,191)$ ) and HIV/HCV-coinfected patients (HIV/HCV group $(n=700))$. A control group (HIV(-)/HCV(-)) was also included $(n=7,496)$.
\end{abstract}

Results: All-HIV group had higher frequencies of severe sepsis (57.7\% versus 39.4\%; $P<0.001)$ than did the control group. Overall, ICU mortality in patients with severe sepsis was much more frequent than that in patients without severe sepsis (other causes) at days 30 and 90 in HIV-infected patients and the control group $(P<0.001)$. Moreover, the all-HIV group in the presence or absence of severe sepsis had a higher percentage of death than did the control group at days $7(P<0.001), 30(P<0.001)$ and $90(P<0.001)$. Besides, the HIV/HCV group had a higher percentage of death, both in patients with severe sepsis and in patients without severe sepsis compared with the HIV group at days $7(P<0.001)$ and $30(P<0.001)$, whereas no differences were found at day 90 . In a bayesian competing-risk model, the HIV/HCV group had a higher mortality risk (adjusted hazard ratio (aHR) = 1.44 (95\% $\mathrm{Cl}=1.30$ to 1.59$)$ and $\mathrm{aHR}=1.57(95 \% \mathrm{Cl}=1.38$ to 1.78$)$ for patients with and without severe sepsis, respectively).

Conclusions: HIV infection was related to a higher frequency of severe sepsis and death among patients admitted to the ICU. Besides, HIV/HCV coinfection contributed to an increased risk of death in both the presence and the absence of severe sepsis.

\section{Introduction}

The introduction of combination antiretroviral therapy (cART) has dramatically decreased the morbidity/mortality associated with human immunodeficiency virus (HIV) infection in industrialized countries, leading to a higher prevalence of persons living with HIV [1]. Furthermore, cART leads to decreased opportunistic infections

\footnotetext{
* Correspondence: sresino@isciii.es

${ }^{\dagger}$ Equal contributors

${ }^{5}$ Unidad de Infección Viral e Inmunidad, Centro Nacional de Microbiología, Instituto de Salud Carlos III, Majadahonda, Madrid, Spain

Full list of author information is available at the end of the article
}

and hospital admissions [2,3]; but the intensive care unit (ICU) admission rate remains constant (or even increased in some instances) during the cART era [4-6]. This may be explained by the fact that HIV-infected patients live longer and are at higher risk of developing nonacquired immunodeficiency syndrome (AIDS) comorbid illnesses, as well as problems related to immune reconstitution inflammatory response syndrome and toxicities related to cART [4,7-9].

Moreover, the impact of HIV infection and cART on the ICU mortality remains controversial [10]. Thus, Chiang et al. [11] reported that outcome during the ICU stay was 
associated with CD4 count and sepsis, but was not associated with cART. However, Amâncio et al. [12] reported that the in-ICU mortality was significantly associated with cART in addition to comorbidities and septic shock. Besides, several authors have reported that HIV-related variables had scarce or no impact on death in patients admitted to the ICU, although they have been closely related to the long-term outcome [5,8,13,14]. Moreover, although Coquet et al. [15] reported an increased ICU survival in the cART era, Vincent et al. [14] reported unchanged overall ICU mortality, but significantly improved 3-month survival of HIV-infected patients admitted to the ICU in the cART era.

Hepatitis $\mathrm{C}$ virus (HCV) is an important cause of acute and chronic hepatitis worldwide. Unfortunately, one fourth of HCV-infected patients will progress to cirrhosis. HCV infection remains the leading cause of decompensated cirrhosis, hepatocellular carcinoma, and liver transplantation $[16,17]$. Chronic hepatitis $\mathrm{C}(\mathrm{CHC})$ is associated with an increased risk for hospital admission and/or mortality, particularly those related to severe liver disease $[18,19]$. This increased mortality rate still exists, even if HCV-specific treatment is administered [9]. Around 20\% of HIV-infected individuals worldwide are chronically coinfected with $\mathrm{HCV}$, with coinfection rates reaching as high as $90 \%$ in persons with a history of injection-drug use [20,21]. Because the course of $\mathrm{HCV}$-associated liver disease may be accelerated in $\mathrm{HIV} / \mathrm{HCV}$-coinfected patients, $\mathrm{HCV}$ has emerged as a major cause of mortality in HIV/HCVcoinfected patients on cART [22]. Fortunately, new direct antiviral agents (DAAs) against $\mathrm{HCV}$ and the recognition of genetic factors that determine $\mathrm{HCV}$ clearance are opening a new era that has been compared with the cART era for HIV infection [23].

The aim of this study was to assess the mortality in HIV-infected patients admitted to the ICU during the modern cART era, and to evaluate the impact of HIV/ HCV coinfection and severe sepsis on ICU mortality.

\section{Materials and methods}

\section{Study design and data source}

We carried out a retrospective cohort study of all consecutive HIV-infected patients older than 18 years who were admitted to the ICU in Spanish hospitals from January 1, 2005, to December 31, 2010.

We also selected a control group of HIV-uninfected patients admitted to the ICU in a proportion of 4:1 regarding to HIV-infected patients involved in the study. This method increases the statistical power and the accuracy of statistical tests [24-26] and is especially useful with a limited number of events. The control group (selective "cohort") was obtained by random selection among the patients older than 18 years with negative results for $\mathrm{HIV}, \mathrm{HCV}$, and HBV testing. To avoid confounding factors, patients were matched for age, gender, trauma, and surgical conditions. More specifically, the selection of the control patients was performed by frequency [27], quartiles of age of HIV-infected patients, and assuming an approximate percentage of men and conditions influencing health status (surgical conditions and trauma).

Data were obtained from the records of the Minimum Basic Data Set (MBDS) of the National Surveillance System for Hospital Data in Spain, provided by the Spanish Ministry of Health. The MBDS is a clinical and administrative database containing information obtained and recorded at time of hospital discharge, with an estimated coverage of $97.7 \%$ and $25 \%$ of total hospital admissions to public and private hospitals, respectively [28]. The MBDS provides the encrypted patient identification number, sex, date of birth, dates of hospital admission and discharge, medical institutions providing the services, the diagnosis and procedure codes according to the International Classification of Diseases, 9th ed, Clinical Modification (ICD-9-CM), and outcome at discharge [29].

The data were treated with full confidentiality, according to Spanish legislation. MBDS is a nonpersonal data extract that is mandatory for hospitals to guarantee the epidemiologic knowledge necessary for driving national health system management. This database is regulated by an organic law that explains how institutions have to proceed with health-related personal data. In this setting, consent is not required because personal data are collected for the exercise of the functions proper to public administrations. The Spanish Ministry of Health confirmed that our study fulfilled all ethical considerations, according to Spanish legislation. The study was approved by the Research Ethics Committee (Comité de Ética de la Investigación y de Bienestar Animal) of the Instituto de Salud Carlos III (Madrid, Spain).

\section{ICD-9-CM codes and study groups}

The ICD-9-CM codes that were used for defining the viral infection status were as follows: (i) HIV infection (042 or V08); (ii) HCV infection (ICD-9-CM codes 070.41, 070.44, 070.51, 070.54, 070.7x, or V02.62); and (iii) HBV infection (ICD-9-CM codes 070.2x, 070.3x, or V02.61).

We selected patients admitted to the ICU who were coded in the MBDS as MIV, which indicates Adult ICU. HBV infection was a criterion for exclusion. Next, we established several groups of patients according to their HIV and HCV status: (i) control group (randomly selected patients without HIV or HCV infections); (ii) all-HIV group (patients with or without HCV coinfection), which was divided into two groups: (a) HIV-monoinfected patients (HIV group) (patients exclusively infected with HIV (HCV infection was excluded)); (b) HIV/HCV-coinfected patients (HIV/HCV group) (patients exclusively coinfected with HIV and HCV). 


\section{Outcome, follow-up, definitions}

The primary outcome was ICU mortality. The secondary outcome was the presence of severe sepsis, which was defined by the presence of an infection-associated diagnosis and organ dysfunction, according to the criteria of Angus et al. [30], by using ICD-9-CM codes (see Additional file 1: Appendix 1 and 2, respectively. The MBDS provides the ICD-9-CM codes for Angus implementation, but not the date of diagnoses. Thus, we were unable to calculate the date of onset of severe sepsis, and severe sepsis was recorded all over the hospital stay.

Length of stay was obtained as the difference, in days, between date of hospital admission and date of discharge or death in the ICU. The day of hospital admission was considered day 0 . Discharge on the same day was considered a 1-day stay. For patients admitted several times to the ICU, only the first admission (also called the index episode) was analyzed.

\section{Statistical analysis}

Overall, results are presented as the median and interquartile range for continuous variables, and frequencies and percentages for categoric data. HIV-infected patients and HIV-uninfected patients were matched by frequencies, which allowed the use of statistical tests for independent groups. Categoric data and proportions were analyzed by using the $\mathrm{X} 2$ test or Fisher Exact test, as required. A $t$ test or Mann-Whitney $U$ test was used to compare continuous variables. All tests were two-tailed with $P$ values $<0.05$ considered significant.

The cumulative mortality rate at days 7,30 , and 90 in patients with ICU admission was calculated without considering censoring. This rate was estimated by dividing the number of deaths by the number of patients admitted to the ICU. Log-linear modeling for contingency tables was used to estimate main and interaction (moderator) effects independently. Moreover, we also calculated the probability of ICU death after taking censoring into account through a semiparametric bayesian model of competing risk [31], which was used to evaluate the association between HIV infection or HIV/HCV coinfection and the risk of ICU mortality, according to the presence of severe sepsis: (a) risk of ICU mortality with severe sepsis; and (b) risk of ICU mortality from other causes (excluding severe sepsis). Inference in our bayesian competing-risk model was based on Markov Chain Monte Carlo (MCMC) simulation algorithms [32].

Moreover, we used the following covariates for adjusting the model: (a) age, sex, trauma, surgical status, Charlson Co-morbidity Index (CCI) (see Additional file 1: Appendix 3 ), and number of organ failures and sites of infection (see Additional file 1: Appendix 4). This semiparametric bayesian model provides the survival probabilities and the hazard ratio (HR). When interpreting results on the basis of calculated survival probabilities, we took the presence of competing risks (severe sepsis and death) into account to prevent biased results [33].

All analyses were performed by using R statistical package version 3.0.2 (GNU General Public License; available at [34]) and BayesX software version 2.1 (GNU General Public License; available at [35]).

\section{Results}

\section{Patient characteristics}

Table 1 shows the epidemiologic and clinical characteristics of patients included in this study. The all-HIV group had a greater length of hospital stay than the control group $(P<0.001)$, as well as higher frequencies of alcohol/ drug abuse, AIDS comorbidities (central nervous system disease, Kaposi sarcoma, non-Hodgkin lymphoma, and wasting syndrome) and $\mathrm{CHC}$ comorbidities (chronic liver disease and cirrhosis and decompensated cirrhosis) $(P<$ 0.05) (Table 1a). Regarding HIV subgroups, the HIV/HCV group had higher frequencies of alcohol/drug abuse and CHC-related comorbidities than the HIV group $(P<0.05)$; whereas the HIV group had a longer hospital stay $(P<$ $0.001)$ and a higher frequency of cancer $(P<0.05)$ than the $\mathrm{HIV} / \mathrm{HCV}$ group (Table $1 \mathrm{~b}$ ).

Table 2 shows the prevalence of processes related to severe sepsis and opportunistic infections among patients admitted to the ICU in this study. The all-HIV group had a higher frequency of severe sepsis $(P<0.001)$, acute organ dysfunctions (except for neurologic dysfunction) $(P<0.05)$, respiratory system infections $(P<0.001)$, central nervous system infections $(P<0.001)$, and opportunistic infections $(P<0.001)$ than the control group (Table 2a). Moreover, the HIV/HCV group had a lower frequency of severe sepsis $(P=0.028)$, respiratory system infections $(P<0.001)$, genitourinary tract infections $(P=0.016)$, and opportunistic infections $(P<0.001)$; and a higher frequency of neurologic and hepatic dysfunction $(P<0.05)$, and digestive system infections $(P<0.001)$ than the HIV group (Table $2 b)$.

\section{Mortality among patients admitted to the ICU}

Table 3 shows the cumulative mortality rate at days 7 , 30, and 90 in patients admitted to the ICU. Overall, the ICU mortality in patients with severe sepsis was much more frequent than in patients without severe sepsis (other causes) at days 30 and 90 for both the all-HIV group and the control group $(P<0.001$; Table $3 \mathrm{a})$, and the HIV group and the HIV/HCV group $(P<0.001$; Table $3 \mathrm{~b})$.

Moreover, the all-HIV group had a higher percentage of death in all analyzed groups: all patients, patients with severe sepsis, and patients without severe sepsis (other causes) at days $7(P<0.001), 30(P<0.001)$, and $90(P<$ 0.001 ) in comparison to the control group (Table $3 a$ ). Besides, the HIV/HCV group had a higher percentage of death for all patients, patients with severe sepsis, and 
Table 1 Epidemiologic and clinical characteristics of patients admitted to the intensive care unit from 2005 to 2010

\begin{tabular}{|c|c|c|c|c|c|c|}
\hline & \multicolumn{3}{|c|}{ 1a: Non-HIV versus all HIV patients } & \multicolumn{3}{|c|}{ 1b: HIV versus HIV/HCV patients } \\
\hline & Control group & All HIV group & $P$ value & HIV group & HIV/HCV group & p-value \\
\hline Number of patients & 7,496 & 1,891 & & $1,191(63 \%)$ & $700(37 \%)$ & \\
\hline Gender (male) & $5,827(77.73 \%)$ & $1,466(77.52 \%)$ & 0.869 & 911 (76.49\%) & $555(79.28 \%)$ & 0.177 \\
\hline Age (years) & $44(36-49)$ & $43(38-48)$ & 0.064 & $43(38-50)$ & $43(39-47)$ & 0.060 \\
\hline Abuse of alcohol and drugs & $2,453(32.72 \%)$ & $942(49.81 \%)$ & $<0.001$ & $494(41.48 \%)$ & $448(64.00 \%)$ & $<0.001$ \\
\hline Length of hospital stay (days) & $5(1-25)$ & $7(2-21)$ & $<0.001$ & $9(2-25)$ & $5(1-14)$ & $<0.001$ \\
\hline \multicolumn{7}{|l|}{ Conditions influencing health status } \\
\hline Surgical conditions (V42, V45) & $302(4.02 \%)$ & $80(4.23 \%)$ & 0.740 & $53(4.45 \%)$ & $27(3.85 \%)$ & 0.616 \\
\hline Trauma (E880* to E929*, E950 to E999*) & $350(4.66 \%)$ & $97(5.12 \%)$ & 0.435 & $64(5.37 \%)$ & $33(4.71 \%)$ & 0.603 \\
\hline \multicolumn{7}{|l|}{ CHC-related comorbidities } \\
\hline Chronic liver disease and cirrhosis & $851(11.35 \%)$ & $248(13.11 \%)$ & 0.036 & $106(8.90 \%)$ & $203(29.00 \%)$ & $<0.001$ \\
\hline Decompensated cirrhosis & $736(9.82 \%)$ & $224(11.85 \%)$ & 0.010 & $82(6.88 \%)$ & $142(20.29 \%)$ & $<0.001$ \\
\hline Liver cancer & $16(0.21 \%)$ & $8(0.42 \%)$ & 0.174 & $2(0.17 \%)$ & $6(0.86 \%)$ & 0.062 \\
\hline Liver transplant & $48(0.64 \%)$ & $11(0.58 \%)$ & 0.900 & $3(0.25 \%)$ & $8(1.14 \%)$ & 0.031 \\
\hline \multicolumn{7}{|l|}{ AIDS-related comorbidities } \\
\hline Central nervous system disease & $31(0.41 \%)$ & $24(1.27 \%)$ & $<0.001$ & $15(1.26 \%)$ & $9(1.29 \%)$ & 1 \\
\hline Cancer & $73(0.97 \%)$ & $91(4.81 \%)$ & $<0.001$ & $72(6.05 \%)$ & $19(2.71 \%)$ & 0.002 \\
\hline Kaposi sarcoma & - & $27(1.43 \%)$ & NA & $25(2.10 \%)$ & $2(0.29 \%)$ & 0.003 \\
\hline Non-Hodgkin lymphoma & $73(0.97 \%)$ & 65 (3.44\%) & $<0.001$ & $49(4.11 \%)$ & $16(2.29 \%)$ & 0.048 \\
\hline Wasting syndrome & $151(2.01 \%)$ & 98 (5.18\%) & $<0.001$ & 65 (5.46\%) & $33(4.71 \%)$ & 0.551 \\
\hline
\end{tabular}

Values are expressed as absolute number (percentage) and median (percentile 25; percentile 75). Values were calculated by $X^{2}$ test and Mann-Whitney $U$ test; and $P$ values in bold indicate statistically significant differences between groups. $\mathrm{HCV}$, hepatitis $\mathrm{C}$ virus; HIV, human immunodeficiency virus.

patients without severe sepsis (other causes) than the HIV group at days $7(P<0.001)$ and $30(P<0.001)$, whereas no differences were found at day 90 (Table $3 \mathrm{~b}$ ).

The possible interaction between the virologic status $\left(\mathrm{HIV}^{-}, \mathrm{HIV}^{+}\right.$, and $\mathrm{HIV}^{+} / \mathrm{HCV}^{+}$) and severe sepsis (present and absent) for death at 7, 30, and 90 days was evaluated. However, we did not find any significant interaction (data not shown), analyzing the main effects independently.

\section{Risk of death in the ICU among HIV-infected patients}

Figure 1 shows the estimated survival function for patients admitted to the ICU, stratified by HIV status (HIV/HCV group versus HIV group), in the presence of competing risks: (i) ICU mortality with severe sepsis (Figure $1 \mathrm{~A}$ ), and (ii) ICU mortality from other causes (without severe sepsis) (Figure 1B). The estimated survival was lower in the HIV/ HCV group than in the HIV group, regardless of the type of competing risk considered. Thus, the HIV/HCV group had higher mortality risk than the HIV group, both in presence of severe sepsis (adjusted hazard ratio $(\mathrm{aHR})=1.44$ $(95 \% \mathrm{CI}=1.30$ to 1.59$)$ ) and in the absence of severe sepsis (other causes) $(\mathrm{aHR}=1.57(95 \% \mathrm{CI}=1.38$ to 1.78$)$ ).

\section{Discussion}

In this study, the major findings were as follows: (a) HIVinfected patients (all-HIV group) had higher frequencies of severe sepsis and opportunistic infections than did HIVseronegative patients (control group); (b) HIV-infected patients had higher mortality than did the control group, independent of the presence of severe sepsis; (c) HIV/HCV coinfection (about one third of HIV-infected patients) had increased risk of ICU mortality, regardless of the presence or absence of severe sepsis.

The spectrum of critical illness in HIV-infected patients has changed since the introduction of cART $[2,3]$. At the beginning of the HIV epidemic, patients admitted to the ICU were mostly young individuals with advanced AIDS-related diseases; but in the cART era, the etiology of ICU admissions changed, whereby fewer patients were admitted to the ICU as a result of opportunistic infections [8,14]. A continual shift occurred toward ICU admissions for non-AIDS-related diagnoses [4]. Among them, sepsis has been responsible for about $12 \%$ to $31 \%$ of $\mathrm{HIV}$-infected patient admissions to the ICU, and is associated with a worse prognosis $[11,36,37]$. In our study, we found that HIV-infected patients had a higher frequency of opportunistic infections than did patients in the control group; despite being in the late period of cART. Additionally, HIVinfected patients had higher frequency of severe sepsis, worse prognosis, and a higher death rate than HIVseronegative subjects. 
Table 2 Summary of diagnoses related to severe sepsis and opportunistic infections in the intensive care unit from 2005 to 2010

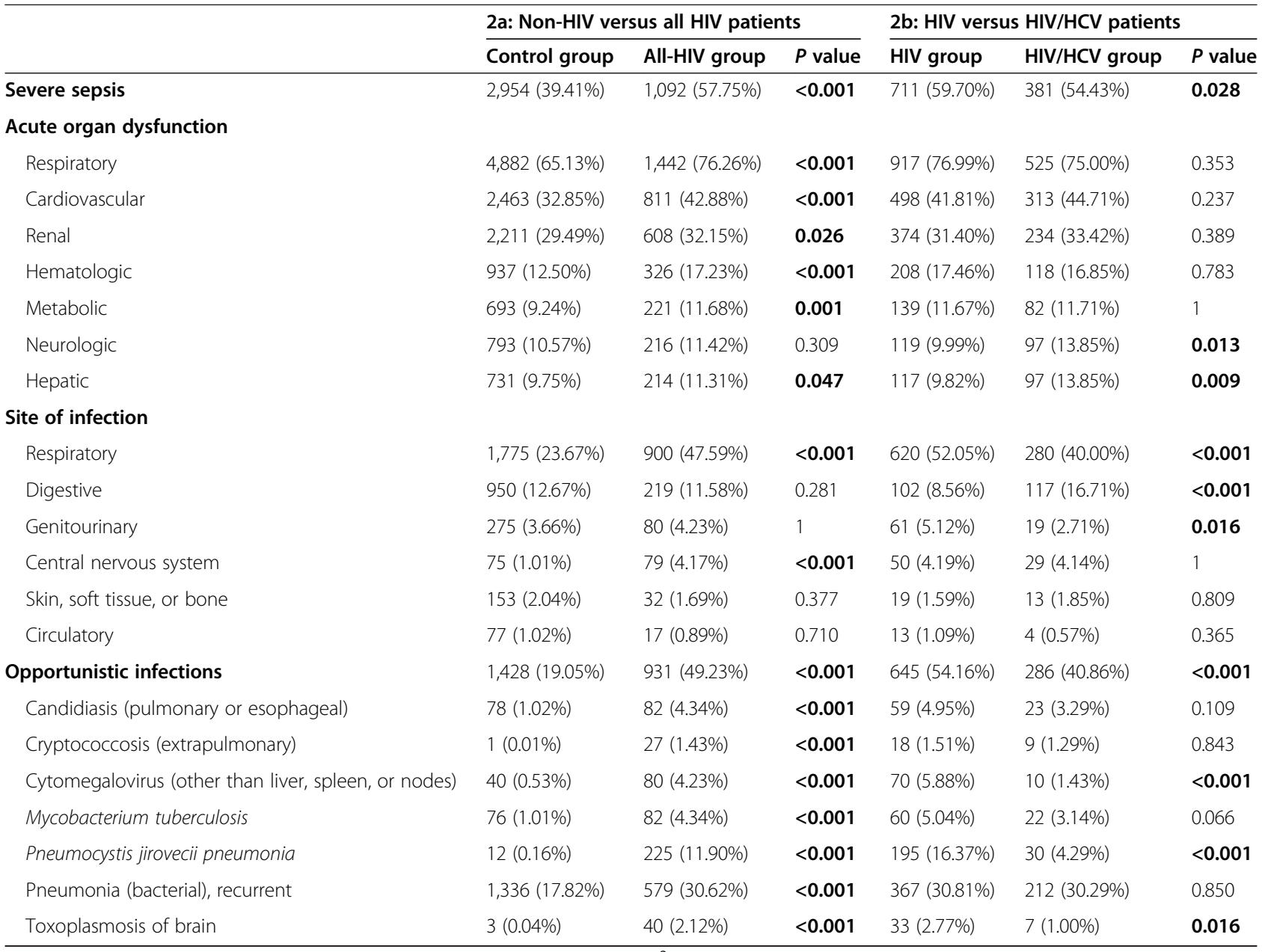

Values are expressed as absolute number (percentage). $P$ values were calculated by $x^{2}$ test, and $P$ values in bold indicates statistically significant differences between groups. HCV, hepatitis C virus; HIV, human immunodeficiency virus.

ICU management of HIV-infected patients in the precART era was widely perceived as futile, as ICU mortality was about 70\% [38]. Subsequently, cART did not seem to improve survival in the ICU compared with the pre-cART era $[14,39]$. In our study, HIV-infected patients had higher ICU mortality than the control group. These differences were regardless of the presence of severe sepsis, although it is noted that the ICU mortality was much more frequent in patients with severe sepsis than in patients without severe sepsis (other causes). These data are consistent with several recent reports [12,40,41]. Akgun et al. [40] found higher frequency of medical ICU admission, 30-day mortality, and mechanical ventilation in HIV-infected compared with HIV-uninfected patients [40]. Furthermore, Silva et al. [41] described a more severe course of sepsis as well as a higher ICU mortality in HIVinfected patients, and Amancio et al. [12]. reported that septic shock was associated with higher ICU mortality. Therefore, according to our data and previously published reports, it is not clear whether cART is associated with an improved survival. In our study, we had no information about compliance with cART, and we could not distinguish between patients with lack of cART initiation and patients with lack of cART benefit.

In our study, when severe sepsis and mortality in the HIV-group were compared with the HIV/HCV group, the data were slightly confusing. The frequency of severe sepsis in the HIV-group and the HIV/HCV group were both higher than 50\%, and around 5\% higher for the HIV group. Conversely, the ICU mortality was higher in the HIV/HCV group than in the HIV group at days 7 and 30 , but no differences were found at day 90 . We have tried to clarify these complex results through a competing-risk model, in which we operated with two different outcome variables (severe sepsis and death) that compete among themselves to prevent biased results (see Statistical Analysis section). This analysis shows that HIV/ HCV coinfection (HIV/HCV group) had an increased risk 
Table 3 Summary of the cumulative mortality rate at days 7, 30, and 90 in patients admitted to the ICU from 2005 to 2010 according to the presence of severe sepsis

\begin{tabular}{|c|c|c|c|c|c|c|c|}
\hline & & \multicolumn{3}{|c|}{ 3a: Non-HIV versus all-HIV patients } & \multicolumn{3}{|c|}{ 3b: HIV versus HIV/HCV patients } \\
\hline & & $\begin{array}{l}\text { Control group } \\
(\text { No. }=7,496)\end{array}$ & $\begin{array}{l}\text { All HIV group } \\
\text { (No. = 1,891) }\end{array}$ & $P$ value $^{(a)}$ & $\begin{array}{l}\text { HIV group } \\
\text { (No. = } 1.191)\end{array}$ & $\begin{array}{l}\text { HIV/HCV group } \\
(\text { No. }=700)\end{array}$ & $P$ value $^{(b)}$ \\
\hline \multirow[t]{6}{*}{ Day 7} & Number of deaths ${ }^{(*)}$ & 2,162 & 690 & & 363 & 327 & \\
\hline & Cumulative mortality rate ${ }^{(* *)}$ & & & & & & \\
\hline & All patients & $28.8(27.6 ; 30.1)$ & $36.5(33.8 ; 39.2)$ & $<0.001$ & $30.5(27.3 ; 33.6)$ & $46.7(41.6 ; 51.8)$ & $<0.001$ \\
\hline & Patients with severe sepsis & $26.1(24.3 ; 27.9)$ & $35.3(31.7 ; 38.7)$ & $<0.001$ & $29.2(25.4 ; 33.2)$ & $46.5(39.6 ; 53.3)$ & $<0.001$ \\
\hline & Patients without severe sepsis & $30.6(28.9 ; 32.2)$ & $38.2(33.9 ; 42.5)$ & $<0.001$ & $32.3(27.2 ; 37.4)$ & $47.1(39.5 ; 54.5)$ & $<0.001$ \\
\hline & $P$ value ${ }^{(c)}$ & $<0.001$ & 0.210 & & 0.292 & 0.941 & \\
\hline \multirow[t]{6}{*}{ Day 30} & Number of deaths ${ }^{(*)}$ & 3819 & 1285 & & 765 & 520 & \\
\hline & Cumulative mortality rate $e^{(* *)}$ & & & & & & \\
\hline & All patients & $50.9(49.3 ; 52.5)$ & $67.9(64.2 ; 71.7)$ & $<0.001$ & $64.2(59.7 ; 68.8)$ & $74.3(67.9 ; 80.7)$ & $<0.001$ \\
\hline & Patients with severe sepsis & $64.0(61.1 ; 66.9)$ & $73.8(68.7 ; 78.9)$ & $<0.001$ & $69.5(63.3 ; 75.6)$ & $81.9(72.8 ; 90.9)$ & $<0.001$ \\
\hline & Patients without severe sepsis & $42.4(40.5 ; 44.3)$ & $59.9(54.6 ; 65.3)$ & $<0.001$ & $56.4(49.7 ; 63.2)$ & $65.2(56.3 ; 74.1)$ & 0.016 \\
\hline & $P$ value ${ }^{(c)}$ & $<0.001$ & $<0.001$ & & $<0.001$ & $<0.001$ & \\
\hline \multirow[t]{6}{*}{ Day 90} & Number of deaths ${ }^{(*)}$ & 4419 & 1531 & & 958 & 573 & \\
\hline & Cumulative mortality rate ${ }^{(* *)}$ & & & & & & \\
\hline & All patients & $58.9(57.2 ; 60.7)$ & $80.9(76.9 ; 85.1)$ & $<0.001$ & $80.4(75.3 ; 85.5)$ & $81.9(75.1 ; 88.6)$ & 0.484 \\
\hline & Patients with severe sepsis & $80.6(77.3 ; 83.8)$ & $90.7(85.1 ; 96.4)$ & $<0.001$ & $90.7(83.7 ; 97.7)$ & $90.8(81.2 ; 99.9)$ & 0.999 \\
\hline & Patients without severe sepsis & $44.9(42.9 ; 46.8)$ & $67.6(61.8 ; 73.3)$ & $<0.001$ & $65.2(57.9 ; 72.4)$ & $71.2(61.9 ; 80.4)$ & 0.092 \\
\hline & $P$ value ${ }^{(c)}$ & $<0.001$ & $<0.001$ & & $<0.001$ & $<0.001$ & \\
\hline
\end{tabular}

Values were expressed as follow: $\left.{ }^{*}\right)$ absolute count; ${ }^{(*)}$ percentage and $95 \%$ confidence interval $(95 \% \mathrm{Cl})$.

$P$-values were calculated by $X^{2}$ test: ${ }^{(a)}$ differences between control group and all HIV group; ${ }^{(b)}$ differences between HIV-group and HIV/HCV group; ${ }^{(c)}$ differences between severe sepsis and other causes. $P$-values in bold indicates statistically significant differences between groups. HCV, hepatitis $C$ virus; HIV, human immunodeficiency virus.

of death compared with HIV-monoinfected patients (HIV group), regardless of the presence of severe sepsis. Thus, the HIV/HCV status per se seems to be deleterious, independent of severe sepsis.

Liver disease has become a major cause of morbidity and mortality among $\mathrm{HIV} / \mathrm{HCV}$-coinfected patients on cART, because HIV infection tends to modify the natural history of $\mathrm{CHC}$ toward a faster progression of liver fibrosis than for HCV-monoinfected patients [22,42,43]. In our study, about $50 \%$ of $\mathrm{HIV} / \mathrm{HCV}$-coinfected patients had comorbidities related to $\mathrm{CHC}$ and end-stage liver disease (ESLD), possibly because of the progressive deterioration from the underlying chronic liver disorder. Hepatic cirrhosis has been reported to be a major independent predictor of ICU mortality, and liver dysfunction results in a greater mortality burden than HIV status [15]. Furthermore, evidence suggests that during cirrhosis, sepsis is accompanied by a markedly imbalanced cytokine response, which converts responses that are normally beneficial for fighting infections into excessive, damaging inflammation [44]. Also, patients with ESLD have enhanced intestinal permeability (leading to translocation of bacteria and their products), imbalanced immune reaction, and aggravated intrahepatic microcirculatory dysfunction and hyperdynamic state, which cause toxin accumulation and immune dysfunction that might further enhance and perpetuate end-stage organ dysfunction [45]. Nevertheless, the occurrence of life-threatening conditions in cirrhosis patients is frequent and would explain higher mortality rates in the HIV/HCV group. [46]. Then, CHC and cirrhosis should be considered targets for improving the survival of HIV-infected patients in the ICU in the future.

The prognostic factors of mortality in HIV-infected patients admitted to the ICU are acute illness severity, poor functional status, low albumin rate, and respiratory failure requiring mechanical ventilation [47-53]. However, specific HIV characteristics (CD4 cell count, plasma HIV-RNA load, HIV-related diagnosis, or antiretroviral therapy) have not been clearly identified as predictors of ICU mortality [4,15,37,38,49-52,54-59], although some reports have associated $\mathrm{CD}^{+}$cell count with mortality risk [11,37]. Our study was retrospective, and the acquisition of the clinical data related to HIV infection and UCI was unavailable from MBDS records. In addition, other variables are difficult to control, such as the $\mathrm{HCV}$ 


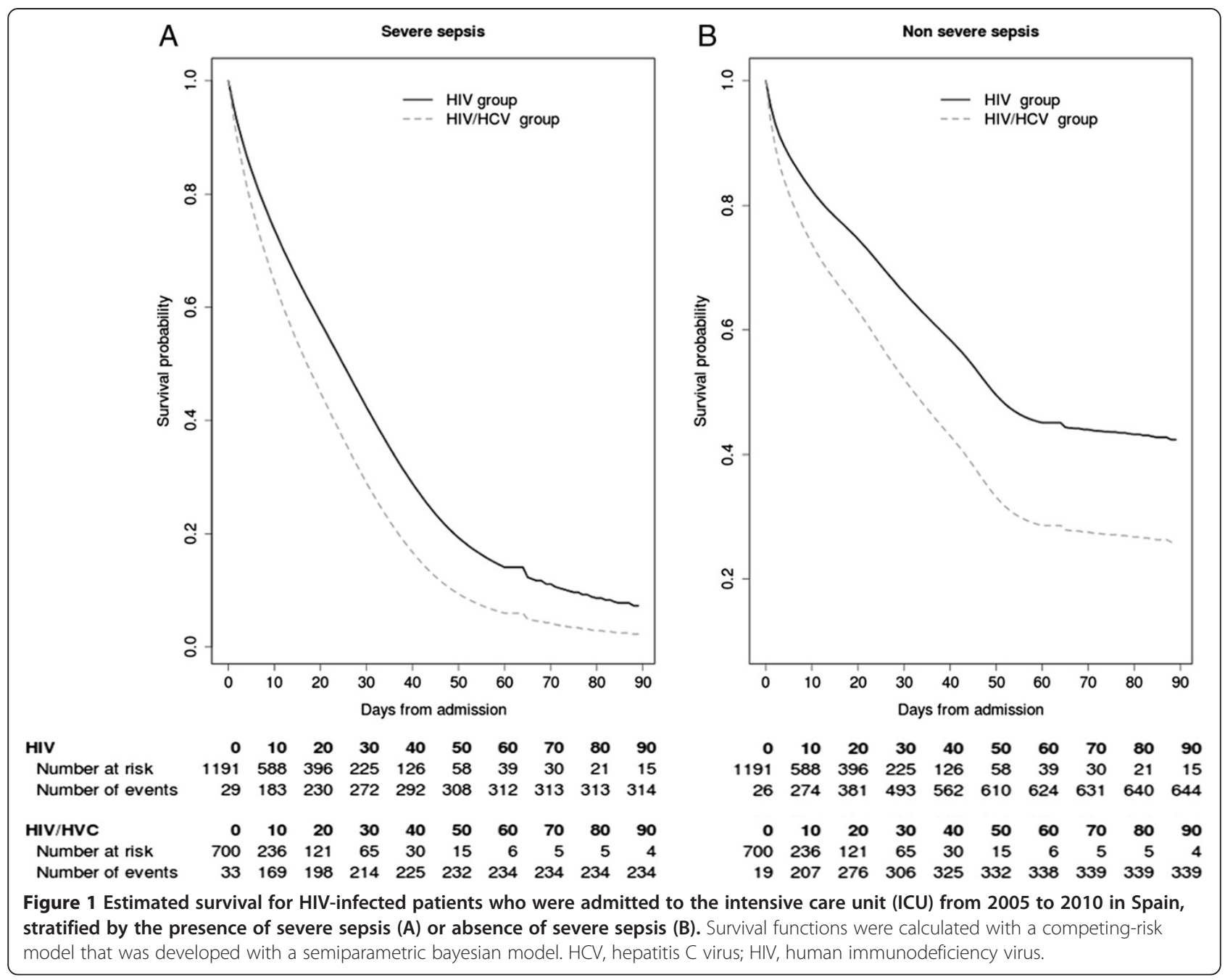

infection, which is strongly linked to intravenous drug use, and the differences between HIV monoinfection and $\mathrm{HIV} / \mathrm{HCV}$ coinfection could partially reflect drug use.

In our study, the time to death or discharge was calculated from hospital rather than ICU admission because the date of ICU admission was not recorded in the MBDS. An immortal time bias could have occurred [60,61], because some patients may have been admitted directly to ICU, whereas other patients may have survived between hospital and ICU admission, and this time period was included in the observation time. However, this theoretic bias should be well balanced in all groups, and only affect the basic value of survival time.

Another limitation due to the use of administrative databases is the inaccuracy in differentiating etiologies of diseases and the reporting of organ dysfunction, engendering confusion bias. In this context, grouping of ICD-9-CM codes into comorbidities, organ dysfunction, and site of infection (Additional file 1: Appendices 1 through 6) may have represented the best approach to solve this issue.
However, the MBDS also provides certain advantages by being a national clinical administrative database, which represents large populations from developed countries. This database has already proven its usefulness in previous assessments of outcomes among patients admitted to the ICU $[62,63]$. Additionally, it allows the detection of trends in important public health issues.

\section{Conclusions}

In conclusion, HIV infection was related to higher frequency of severe sepsis and death among patients admitted to the ICU. Also, HIV/HCV coinfection contributed to an increased risk of death in both the presence and absence of severe sepsis.

\section{Key messages}

(1) HIV-infected patients had higher frequencies of severe sepsis and opportunistic infections than did HIV-seronegative patients. 
(2) HIV-infected patients had higher mortality than the control group, independent of the presence of severe sepsis.

(3) $\mathrm{HIV} / \mathrm{HCV}$ coinfection (about one third of HIV-infected patients) had increased risk of ICU mortality, regardless of the presence of severe sepsis.

\section{Additional file}

Additional file 1: Appendix 1. International Classification of Diseases, 9th Revision, Clinical Modification (ICD-9-CM) codes for bacterial and fungal infections. Appendix 2. International Classification of Diseases, 9th Revision, Clinical Modification (ICD-9-CM) codes for acute organ dysfunction. Appendix 3. International Classification of Diseases, 9th Revision, Clinical Modification (ICD-9-CM) coding algorithms for Charlson comorbidities. Appendix 4. International Classification of Diseases, 9th Revision, Clinical Modification (ICD-9-CM) codes were used to identify the source of infection causing sepsis. Appendix 5. International Classification of Diseases, 9th Revision, Clinical Modification (ICD-9-CM) codes for AIDS and $\mathrm{CHC}$ related diagnoses. Appendix 6. International Classification of Diseases, 9th Revision, Clinical Modification (ICD-9-CM) codes for comorbid diseases.

\section{Abbreviations}

AIDS: Acquired immunodeficiency syndrome; CART: combination antiretroviral therapy; CCl: Charlson co-morbidity index; CHC: chronic hepatitis C; DAA: direct antiviral agent; ESLD: end-stage liver disease; HCV: hepatitis C virus; HIV: human immunodeficiency virus; ICD-9-CM: International Classification of Diseases, 9th ed, Clinical Modification; ICU: intensive care unit; MBDS: minimum basic data set.

\section{Competing interests}

The authors declare that they have no competing interests.

\section{Authors' contributions}

JM participated in the study concept, design, and drafting of the manuscript. AAM participated in the design of the study and performed the statistical analysis. AB participated in the drafting of the manuscript and performed a critical revision for intellectual content. MAJS participated in the drafting of the manuscript and performed a critical revision for intellectual content. SR conceived of the study, participated in its design and coordination, and helped to draft the manuscript. All authors read and approved the final manuscript.

\section{Acknowledgements}

We thank the Subdirección General del Instituto de Información Sanitaria (Ministerio de Sanidad, Servicios Sociales e Igualdad) for providing the information on which this study is based.

\section{Funding/Support}

This research has been supported by Instituto de Salud Carlos III (grant numbers PI1 1/00245 to SR and PI12/00019 to AAM). MAJS is supported by a contract of Instituto de Salud Carlos III (grant number CD13/00013).

\section{Author details}

'Departamento de Medicina, Universidad del País Vasco UPV/EHU, Vitoria-Gasteiz, Spain. ${ }^{2}$ Servicio de Urgencias, Hospital Universitario de Araba, Vitoria-Gasteiz, Spain. ${ }^{3}$ Unidad de Medicina Preventiva y Salud Pública, Facultad de Ciencias de la Salud, Universidad Rey Juan Carlos, Alcorcón, Madrid, Spain. ${ }^{4}$ Université de Bordeaux, INSERM U657, Pharmaco-épidémiologie et évaluation de l'impact des produits de santé sur les populations, F-33000 Bordeaux cedex, France. ${ }^{5}$ Unidad de Infección Viral e Inmunidad, Centro Nacional de Microbiología, Instituto de Salud Carlos III, Majadahonda, Madrid, Spain.
Received: 27 January 2014 Accepted: 23 July 2014

Published online: 27 August 2014

\section{References}

1. WHO: Global HIV/AIDS response: Epidemic Update and Health Sector Progress Towards Universal Access. In Progress Report 2011. Geneva, Switzerland: World Health Organization; 2011.

2. Engsig FN, Hansen ABE, Gerstoft J, Kronborg G, Larsen CS, Obel N: Inpatient admissions and outpatient visits in persons with and without HIV infection in Denmark, 1995-2007. Aids 2010, 24:457-461.

3. Crum-Cianflone NF, Grandits G, Echols S, Ganesan A, Landrum M, Weintrob A, Barthel R, Agan B, Program IDCR: Trends and causes of hospitalizations among HIV-infected persons during the late HAART era: what is the impact of CD4 counts and HAART use? J Acquir Immune Defic Syndr 2010, 54:248-257.

4. Narasimhan M, Posner AJ, DePalo VA, Mayo PH, Rosen MJ: Intensive care in patients with HIV infection in the era of highly active antiretroviral therapy. Chest 2004, 125:1800-1804.

5. Barbier F, Coquet I, Legriel S, Pavie J, Darmon M, Mayaux J, Molina JM, Schlemmer B, Azoulay E: Etiologies and outcome of acute respiratory failure in HIV-infected patients. Intensive Care Med 2009, 35:1678-1686.

6. Tan DH, Walmsley SL: Management of persons infected with human immunodeficiency virus requiring admission to the intensive care unit. Crit Care Clin 2013, 29:603-620.

7. Akgun KM, Gordon K, Pisani M, Fried T, McGinnis KA, Tate JP, Butt AA, Gibert CL, Huang L, Rodriguez-Barradas MC, Rimland D, Justice AC, Crothers K: Risk factors for hospitalization and medical intensive care unit (MICU) admission among HIV-infected Veterans. J Acquir Immune Defic Syndr 2013, 62:52-59.

8. Casalino E, Wolff M, Ravaud P, Choquet C, Bruneel F, Regnier B: Impact of HAART advent on admission patterns and survival in HIV-infected patients admitted to an intensive care unit. Aids 2004, 18:1429-1433.

9. Akgun KM, Huang L, Morris A, Justice AC, Pisani M, Crothers K: Critical illness in HIV-infected patients in the era of combination antiretroviral therapy. Proc Am Thorac Soc 2011, 8:301-307.

10. Akgun KM, Pisani M, Crothers $K$ : The changing epidemiology of HIV-infected patients in the intensive care unit. J Intensive Care Med 2011, 26:151-164.

11. Chiang HH, Hung CC, Lee CM, Chen HY, Chen MY, Sheng WH, Hsieh SM, Sun HY, Ho CC, Yu CJ: Admissions to intensive care unit of HIV-infected patients in the era of highly active antiretroviral therapy: etiology and prognostic factors. Crit Care 2011, 15:R202.

12. Amancio FF, Lambertucci JR, Cota GF, Antunes CM: Predictors of the short- and long-term survival of HIV-infected patients admitted to a Brazilian intensive care unit. Int J STD AIDS 2012, 23:692-697.

13. Casalino E, Mendoza-Sassi G, Wolff M, Bedos JP, Gaudebout C, Regnier B, Vachon F: Predictors of short- and long-term survival in HIV-infected patients admitted to the ICU. Chest 1998, 113:421-429.

14. Vincent B, Timsit JF, Auburtin M, Schortgen F, Bouadma L, Wolff M, Regnier B: Characteristics and outcomes of HIV-infected patients in the ICU: impact of the highly active antiretroviral treatment era. Intensive Care Med 2004, 30:859-866.

15. Coquet I, Pavie J, Palmer P, Barbier F, Legriel S, Mayaux J, Molina JM, Schlemmer B, Azoulay E: Survival trends in critically ill HIV-infected patients in the highly active antiretroviral therapy era. Crit Care 2010, 14:3.

16. Shepard CW, Finelli L, Alter MJ: Global epidemiology of hepatitis C virus infection. Lancet Infect Dis 2005, 5:558-567.

17. Seeff LB: The history of the "natural history" of hepatitis C (1968-2009). Liver Int 2009, 29:89-99.

18. McDonald SA, Hutchinson SJ, Mills PR, Bird SM, Cameron S, Dillon JF, Goldberg DJ: The influence of hepatitis $C$ and alcohol on liver-related morbidity and mortality in Glasgow's injecting drug user population. J Viral Hepat 2011, 18:e126-e133.

19. Berenguer J, Alejos B, Hernando V, Viciana P, Salavert M, Santos I, GomezSirvent JL, Vidal F, Portilla J, Del Amo J: Trends in mortality according to hepatitis $C$ virus serostatus in the era of combination antiretroviral therapy. Aids 2012, 26:2241-2246.

20. Gonzalez-Garcia JJ, Mahillo B, Hernandez S, Pacheco R, Diz S, Garcia P, Esteban H, Arribas JR, Quereda C, Rubio R, Díez J, Moreno S, Vázquez-Rodríguez JJ: Prevalences of hepatitis virus coinfection and indications for chronic hepatitis $C$ virus treatment and liver transplantation in Spanish HIV-infected patients: The GESIDA 29/02 and 
FIPSE 12185/01 Multicenter Study. Enferm Infecc Microbio/ Clin 2005, 23:340-348.

21. Kim AY, Chung RT: Coinfection with HIV-1 and HCV: a one-two punch. Gastroenterology 2009, 137:795-814.

22. Lopez-Dieguez M, Montes ML, Pascual-Pareja JF, Quereda C, Von Wichmann MA, Berenguer J, Tural C, Hernando A, Gonzalez-Garcia J, Serrano L, Arribas JR: The natural history of liver cirrhosis in HIV-hepatitis $C$ virus-coinfected patients. Aids 2011, 25:899-904.

23. Soriano V, Vispo E, Fernandez-Montero JV, Labarga P, Barreiro P: Update on HIV/HCV coinfection. Curr HIV/AIDS Rep 2013, 10:226-234

24. Bruce N, Pope D, Stanistreet D: Case-control studies. In Quantitative Methods for Health Research: A Practical Interactive Guide to Epidemiology and Statistics. London: John Wiley \& Sons, Ltd; 2008:257-305.

25. Ury HK: Efficiency of case-control studies with multiple controls per case: continuous or dichotomous data. Biometrics 1975, 31:643-649.

26. Taylor JM: Choosing the number of controls in a matched case-control study: some sample size, power and efficiency considerations. Stat Med 1986, 5:29-36.

27. Gail MH: Frequency matching. In Encyclopedia of Biostatistics. 2nd edition. Edited by Armitage P, Colton T. Hoboken, NJ: John Wiley \& Sons, Ltd; 2005

28. Subdirección General de Desarrollo: Instituto Nacional de Salud. Ministerio de Sanidad y Consumo. 2001, [http://www.ingesa.msc.es/estadEstudios/ documPublica/CMBD-2001.htm] Conjunto Mínimo Básico de Datos Hospitales de Insalud 2001.

29. Alkaline Software Inc: The Web's Free 2014 Medical Coding Reference. 2010 ICD-9-CM Diagnosis Codes. Available from: http://www.icd9data. com/2007/Nolume1/140-239/default.htm.

30. Angus DC, Linde-Zwirble WT, Lidicker J, Clermont G, Carcillo J, Pinsky MR: Epidemiology of severe sepsis in the United States: analysis of incidence, outcome, and associated costs of care. Crit Care Med 2001, 29:1303-1310.

31. Kneib T, Hennerfeind A: Bayesian semi parametric multi-state models. Stat Model 2008, 8:169-198.

32. Gelfand AE, Smith AFM: Sampling-based approaches to calculating marginal densities. J Am Stat Assoc 1990, 85:398-409.

33. Andersen PK, Geskus RB, de Witte T, Putter H: Competing risks in epidemiology: possibilities and pitfalls. Int J Epidemio/ 2012, 41:861-870.

34. The R Foundation for Statistical Computing: $R$ version 3.0.2. Available from: http://www.r-project.org/.

35. BayesX: Bayesian Inference in Structured Additive Regression Models. Version 2.1. Available from: http://www.stat.uni-muenchen.de/ bayesx/ bayesx.html.

36. Davaro RE, Thirumalai A: Life-threatening complications of HIV infection. J Intensive Care Med 2007, 22:73-81.

37. Croda J, Croda MG, Neves A, de Sousa dos Santos S: Benefit of antiretroviral therapy on survival of human immunodeficiency virus-infected patients admitted to an intensive care unit. Crit Care Med 2009, 37:1605-1611.

38. Huang L, Quartin A, Jones D, Havlir DV: Intensive care of patients with HIV infection. N Engl J Med 2006, 355:173-181.

39. Morris A, Creasman J, Turner J, Luce JM, Wachter RM, Huang L: Intensive care of human immunodeficiency virus-infected patients during the era of highly active antiretroviral therapy. Am J Respir Crit Care Med 2002, 166:262-267.

40. Akgun KM, Tate JP, Pisani M, Fried T, Butt AA, Gibert CL, Huang L, Rodriguez-Barradas MC, Rimland D, Justice AC, Crothers K: Medical ICU admission diagnoses and outcomes in human immunodeficiency virus-infected and virus-uninfected veterans in the combination antiretroviral era. Crit Care Med 2013, 41:1458-1467.

41. Silva JM Jr, dos Santos SS: Sepsis in AIDS patients: clinical, etiological and inflammatory characteristics. J Int AIDS Soc 2013, 16:17344.

42. Macias J, Berenguer J, Japon MA, Giron JA, Rivero A, Lopez-Cortes LF, Moreno A, Gonzalez-Serrano M, Iribarren JA, Ortega E, Miralles P, Mira JA, Pineda JA: Fast fibrosis progression between repeated liver biopsies in patients coinfected with human immunodeficiency virus/hepatitis $C$ virus. Hepatology 2009, 50:1056-1063.

43. Lo Re V, Kostman JR, Amorosa VK: Management complexities of HIV/ hepatitis $C$ virus coinfection in the twenty-first century. Clin Liver Dis 2008, 12:587-609. ix

44. Gustot T, Durand F, Lebrec D, Vincent $J$, Moreau R: Severe sepsis in cirrhosis. Hepatology 2009, 50:2022-2033.
45. Laleman W, Verbeke L, Meersseman P, Wauters J, van Pelt J, Cassiman D, Wilmer A, Verslype C, Nevens F: Acute-on-chronic liver failure: current concepts on definition, pathogenesis, clinical manifestations and potential therapeutic interventions. Expert Rev Gastroenterol Hepatol 2011, 5:523-537. Quiz, 537

46. Moreau R, Hadengue A, Soupison T, Kirstetter P, Mamzer MF, Vanjak D, Vauquelin P, Assous M, Sicot C: Septic shock in patients with cirrhosis: hemodynamic and metabolic characteristics and intensive care unit outcome. Crit Care Med 1992, 20:746-750.

47. Japiassu AM, Amancio RT, Mesquita EC, Medeiros DM, Bernal HB, Nunes EP Luz PM, Grinsztejn B, Bozza FA: Sepsis is a major determinant of outcome in critically ill HIV/AIDS patients. Crit Care 2010, 14:R152.

48. Greenberg JA, Lennox JL, Martin GS: Outcomes for critically ill patients with HIV and severe sepsis in the era of highly active antiretroviral therapy. J Crit Care 2012, 27:51-57.

49. Powell K, Davis JL, Morris AM, Chi A, Bensley MR, Huang L: Survival for patients with HIV admitted to the ICU continues to improve in the current era of combination antiretroviral therapy. Chest 2009, 135:11-17.

50. Nickas G, Wachter RM: Outcomes of intensive care for patients with human immunodeficiency virus infection. Arch Intern Med 2000, 160:541-547.

51. Afessa B, Green B: Clinical course, prognostic factors, and outcome prediction for HIV patients in the ICU: The PIP (pulmonary complications, ICU support, and prognostic factors in hospitalized patients with HIV) study. Chest 2000, 118:138-145.

52. Alves C, Nicolas JM, Miro JM, Torres A, Agusti C, Gonzalez J, Rano A, Benito N, Moreno A, Garcia F, Millá J, Gatell JM: Reappraisal of the aetiology and prognostic factors of severe acute respiratory failure in HIV patients. Eur Respir J 2001, 17:87-93.

53. Vargas-Infante YA, Guerrero ML, Ruiz-Palacios GM, Soto-Ramirez LE, Del Rio C, Carranza J, Dominguez-Cherit G, Sierra-Madero JG: Improving outcome of human immunodeficiency virus-infected patients in a Mexican intensive care unit. Arch Med Res 2007, 38:827-833.

54. Morris A, Wachter RM, Luce J, Turner J, Huang L: Improved survival with highly active antiretroviral therapy in HIV-infected patients with severe Pneumocystis carinii pneumonia. Aids 2003, 17:73-80.

55. Miller RF, Allen E, Copas A, Singer M, Edwards SG: Improved survival for HIV infected patients with severe Pneumocystis jirovecii pneumonia is independent of highly active antiretroviral therapy. Thorax 2006, 61:716-721.

56. Dickson SJ, Batson S, Copas AJ, Edwards SG, Singer M, Miller RF: Survival of HIV-infected patients in the intensive care unit in the era of highly active antiretroviral therapy. Thorax 2007, 62:964-968.

57. Khouli H, Afrasiabi A, Shibli M, Hajal R, Barrett CR, Homel P: Outcome of critically ill human immunodeficiency virus-infected patients in the era of highly active antiretroviral therapy. J Intensive Care Med 2005, 20:327-333.

58. van Lelyveld SF, Wind CM, Mudrikova T, van Leeuwen HJ, de Lange DW, Hoepelman Al: Short- and long-term outcome of HIV-infected patient admitted to the intensive care unit. Eur J Clin Microbiol Infect Dis 2011, 30:1085-1093.

59. Morquin D, Le Moing V, Mura T, Makinson A, Klouche K, Jonquet O, Reynes J, Corne P: Short- and long-term outcomes of HIV-infected patients admitted to the intensive care unit: impact of antiretroviral therapy and immunovirological status. Ann Intensive Care 2012, 2:25.

60. Ho AM, Dion PW, Ng CS, Karmakar MK: Understanding immortal time bias in observational cohort studies. Anaesthesia 2013, 68:126-130.

61. Levesque LE, Hanley JA, Kezouh A, Suissa S: Problem of immortal time bias in cohort studies: example using statins for preventing progression of diabetes. BMJ 2010, 340:b5087.

62. Shen HN, Lu CL, Yang HH: Epidemiologic trend of severe sepsis in Taiwan from 1997 through 2006. Chest 2010, 138:298-304.

63. Martin GS, Mannino DM, Eaton S, Moss M: The epidemiology of sepsis in the United States from 1979 through 2000. N Engl J Med 2003, 348:1546-1554.

doi:10.1186/s13054-014-0475-3

Cite this article as: Medrano et al:: Mortality of patients infected with HIV in the intensive care unit (2005 through 2010): significant role of chronic hepatitis C and severe sepsis. Critical Care 2014 18:475. 